Año 9. Núm. 24 (Julio- diciembre 2016)

http://revistainvestigacionacademicasinfrontera.com
Revista de Investigación

Académica sin Frontera

ISSN: 2007-8870

Recibido el 15 de mayo de 2016.

Dictamen favorable el 27 diciembre de 2016.

\title{
Análisis comparativo de los inimputables ante el sistema tradicional y el sistema acusatorio penal
}

\section{Alejandra Romero Núñez}

\section{RESUMEN.}

Según el autor José Ángel Medina Narváez. - " inimputabilidad es la situación fáctica en que el agente del delito, al momento de realizar el hecho típico, no tiene la capacidad de comprender el carácter ilícito de aquel o de conducirse de acuerdo con esa comprensión en virtud de padecer trastorno mental". Se realiza un análisis comparativo en el sistema tradicional penal y el nuevo sistema penal acusatorio oral, donde el sistema tradicional fue de menor relevancia para el proceso de personas inimputables. En el nuevo sistema acusatorio, que entro en vigor en el presente año 2016, se crea un nuevo proceso más factible y garantista para las personas que padecen algún desorden psicopatológico. En la federación mexicana cuando se suscitan este tipo de procesos de personas inimputables ante un órgano jurisdiccional deberá ser procesado conforme a lo establecido en el código nacional de procedimientos penales, con el nuevo sistema acusatorio oral.

\section{INTRODUCCION}

Durante el presente trabajo de investigación abordaremos uno de los temas con mayor relevancia en nuestro sistema penal. Daremos a conocer cuáles son las diferencias entre en sistema tradicional penal y el sistema acusatorio oral en el ámbito del procedimiento para los inimputables. 


\section{http://revistainvestigacionacademicasinfrontera.com}

A diferencia del sistema acusatorio oral, en el sistema tradicional penal que se aplicó durante años en nuestra nación mexicana, encontraremos puntos relevantes y violatorios al debido proceso para los inimputables, dando a conocer que se llevaba a cabo un proceso "especial" el cual nos dejaba una interrogante al no conocer a que se refería esencialmente.

Alcanzaremos muchos puntos relevantes acerca de esta problemática, como conocer el procedimiento adecuado y como deben de ser tratadas las personas a las que se les presenta este tipo de situación. Los órganos judiciales y ejecutivos que tengan en posesión a este tipo de personas deben de realizar las averiguaciones previas para dar a conocer su respectivo tratamiento.

Por lo cual nos dimos a la tarea de criticar, investigar y conocer más acerca de este tema que es de suma importancia para los conocedores del derecho y para los que se encuentran es esta situación.

Es trascendente comprender el proceso para los inimputables en el nuevo sistema acusatorio oral ya que esté entro en vigor en el presente año 2016 el cual rige los procesos penales en nuestra república mexicana. Que a continuación presentamos.

\section{PLANTEAMIENTO DEL TEMA.}

A consecuencia se puede determinar que la persona inimputable es toda aquella que sufre de trastornos mentales ya sean permanentes o transitorios a causa de ello se presentará un procedimiento especial llevado a cabo hoy en día por los juzgados aptos para llevar a cabo este tipo de problemática. 
A continuación se llevara a cabo un análisis comparativo entre el sistema tradicional penal y el nuevo sistema de acusatorio oral.

\section{REFERENCIAS TEÓRICAS}

Para comprender esta problemática necesitamos conocer los siguientes conceptos:

Inimputabilidad.- como lo menciona el autor, "inimputabilidad no implica, necesariamente, la ausencia total de determinismo del sujeto, sino únicamente que está impedido para comprender la licitud de su actuar". ( Medina Narváez, 2016, pág. 267)

Imputabilidad.- según el autor "es una calidad personal del sujeto activo toda vez que ella surge al cumplir aquel cierta edad, la cual hace que jurídicamente entre en posesión de una capacidad psíquica que le atribuye la posibilidad de argumentar, juzgar, seleccionar y decidir determinada voluntad ilícita". (Rodríguez Navarrete , 2016, pág. 266)

Culpabilidad.- según el autor se refiere que "etimológicamente, culpabilidad proviene del latín culpabilis, que se refiere atribuir algo deshonroso a alguien". (Estrada Álvarez , 2009, pág. 51)

\section{Los inimputables en el Sistema Tradicional Inquisitorio.}

En el procedimiento penal anterior se nos dice que tan pronto se sospeche que el imputado este loco, idiota o imbécil que se sufra, una enfermedad mental, el tribunal lo mandara a examinar por peritos médicos. Sin continuar el procedimiento de forma ordinaria si existe motivo fundado, se ordenara reclusión provisional al 


\section{http://revistainvestigacionacademicasinfrontera.com}

ISSN: 2007-8870

inculpado en instituciones psiquiátricas." Cabe destacar que en la actualidad dichos términos como loco idiota imbécil han quedado en desuso debido a que constituye una terminología ofensiva y discriminatoria contraria al artículo primero constitucional".

Cuando se compruebe que el inculpado está en uno de estos casos, se detendrá el proceso ordinario, se le abrirá un juicio especial y se dejara al criterio del tribunal la investigación correspondiente al delito del imputado.

Si se prueba que el inculpado tubo participación en el delito ante ministerio público en audiencia frente del defensor si lo tuviere el tribunal resolverá el caso ordenando su reclusión en términos del artículo 19 del código penal de sonora que nos dice que las sanciones y medidas de seguridad serán la reclusión de la persona que sufra un proceso psicopatológico permanente o transitorio que lo hagan inimputable.

Si en el trascurso de proceso el inculpado enloquece se le suspenderá el procedimiento en los términos del artículo 419 del código de procedimientos penales, solo se podrá suspender el proceso en los casos siguientes cuando el imputado enloquezca y por tal motivo deberá ser trasladándolo a instituciones psiquiátricas, escuelas, departamentos especiales u hospitales adecuados para su respectivo tratamiento y la vigilancia del recluido quedará a cargo del órgano que designe el ejecutivo del estado.

Por ello podemos determinar que estos procesos aparentemente "especiales" no cumplen con el debido proceso que deben de manejar para llevar a cabo el procedimiento de una manera más factible y oportuna para la persona inimputable que se encuentra bajo esa circunstancia, lo anterior conforme al artículo 14 constitucional. 


\section{http://revistainvestigacionacademicasinf rontera.com}

ISSN: 2007-8870

El numeral 15 fracción VII del Código Penal Federal que se refiere a causas excluyentes de responsabilidad, expresa: "Al momento de realizar el hecho típico, el agente no tenga la capacidad de comprender el carácter ilícito de aquel o de conducirse de acuerdo con esa comprensión, en virtud de padecer trastorno mental o desarrollo intelectual retardado, a no ser que el agente hubiere provocado su trastorno mental dolosa o culposamente, en cuyo caso responderá por el resultado típico siempre y cuando lo haya previsto o le fuere previsible.

Cuando el agente del delito se encuentre en su supuesto de inimputable no podrá someterse a las leyes penales al igual que las personas normales si no que se regirán conforme a los siguientes artículos 67,68 y 69 bis señalados en el código penal federal, en el caso de las personas que se le consideraran como inimputables se debe de imponer las siguientes medidas de tratamiento aplicable en el internamiento o en libertad, si se trata de internamiento de la persona inimputable será remitido a la institución correspondiente para su tratamiento.

Estas personas deberán ser entregadas por una autoridad judicial o ejecutora o a quien le corresponda hacerse cargo de ellos, se deben de obligar a tomar las medidas correspondientes para su tratamiento y vigilancia, en ningún caso la medida de tratamiento que impondrá el juez penal excederá de la duración que corresponda al máximo de una pena aplicable del delito.

Ahora bien, el criterio de la Corte ha sido el siguiente, Si la capacidad del imputable, de comprender el carácter ilícito del hecho, a juicio de juzgador según proceda se le impondrá hasta dos terceras parte de la pena que correspondería al delito cometido conforme al hecho. (En la tesis jurisprudencial de la novena época numeral 166644). 


\section{http://revistainvestigacionacademicasinfrontera.com}

Según la legislación del distrito federal, la imposición de una medida de seguridad consistente en el tratamiento en internamiento o en libertad, requiere la acreditación de que cometieron un hecho típico y antijurídico.

Del contenido de los artículos 5, párrafo segundo y 62, párrafo tercero, del Código Penal para el Distrito Federal, que establecen el principio de culpabilidad y el tratamiento de inimputables, respectivamente, se advierte que éstos no son culpables y por ello no cometen un delito con todos sus elementos, por lo que no se les puede imponer pena alguna, precisamente por faltar el presupuesto de la culpabilidad; sin embargo, dicho Código Penal prevé para estos casos la imposición de una medida de seguridad y para que ésta pueda imponerse requiere acreditarse que el sujeto haya cometido un injusto penal, es decir, un hecho típico y antijurídico, mas no una infracción, siendo la consecuencia jurídica para el inimputable

\section{Los inimputables en el Sistema Penal Acusatorio}

En el nuevo sistema acusatorio oral, a diferencia del antiguó sistema tradicional penal que fue aplicado durante años en nuestro territorio nacional, hoy en día ha cambiado la manera de procesar a este tipo de personas que sufren de desórdenes psicopatológicos gracias al nuevo sistema acusatorio oral que entro en vigor en junio del 2016 en Sonora. Cuando llega una persona con carácter de inimputable ante el órgano jurisdiccional competente se le llevará a cabo el proceso adecuado que se rige bajo los artículos 414, 415, 416, 417, 418, 419 del código nacional de procedimientos penales.

Si en el transcurso de la audiencia inicial aparecen indicios de que el imputado se encuentra en uno de los supuestos de inimputabilidad, previstos por el código penal aplicable, el juez de control o cualquiera de las partes podrán ordenar la práctica de 


\section{http://revistainvestigacionacademicasinfrontera.com}

peritajes que para ello se pueda determinar si verdaderamente la persona es inimputable.

En caso de serlo si esta inimputabilidad es permanente o transitoria se comprueba que esta fue provocada por el imputado o se fue imputado la audiencia continuara con las mismas reglas pero para esto se tendrá que proveer de ajustes razonables los cuales determinara el juez de control.

Cuando se encuentre retenida la persona el ministerio público, aplicara los ajustes razonables para evitar un mayor daño de vulnerabilidad al respecto de su integridad, si el imputado fue vinculado a proceso y se prevé que se encuentra en situación de inimputabilidad, las partes o el juez de control podrán solicitar los peritajes necesarios para acreditar tal extremo, y ver si la inimputabilidad que presente pudo ser propiciado o no por la persona.

Si ya determinado que el estado de inimputabilidad del sujeto, al procedimiento

Ordinario se le aplicaran las observaciones del debido proceso ya con los ajustes del procedimiento que en caso concreto acuerde el juez de control, escuchando al ministerio público y al defensor para acreditar la participación de la persona inimputable en el hecho atribuido, para lo cual poder determinar las medidas de seguridad pertinentes.

En los casos de que este estado de inimputabilidad cese se seguirá con el procedimiento ordinario sin tomar en cuenta los ajustes que pudieron a ver realizado, al procedimiento para poder imponer medidas cautelares a personas inimputables, mediante las reglas del proceso ordinario, con los ajustes que disponga el juez de control para el caso que sea procedente. El ser inimputable no da la razón suficiente para poder imponer medidas cautelares . 
Para la resolución del caso, comprobado que existe el hecho que la ley señala como delito y que el inimputable intervino, ya sea su participación como autor o participe, sin que pueda operar alguna causa de justificación a favor prevista en los códigos sustantivos. El tribunal de enjuiciamiento resolverá el caso si hay base suficiente para la imposición de la medida de seguridad, le corresponderá al órgano judicial para determinar la individualización de la medida atendiendo las necesidades de prevención especial positiva y respetando los criterios de proporcionalidad y de mínima intervención si estos requisitos no se acreditan, el tribunal absolverá al inimputable. La medida de seguridad no podrá tener mayor duración a la pena que se le pudiera aplicar en el caso de que sea imputable, la medida de seguridad consistente en el tratamiento en internamiento o en libertad.

\section{METODOLOGÍA}

Una vez comprendidos estos conceptos analizaremos a fondo como se lleva acabo el procedimiento tradicional penal para personas inimputables con forme a los artículos 74, 75, y 76 del código penal y 446, 447, 448, 449, 450 del código abrogado de procedimientos penales para el estado de sonora.

\section{RESULTADOS Y CONCLUSIÓN:}

Al concluir esta investigación conocimos las ventajas con las que cuanta el nuevo sistema acusatorio oral en cuestión de los inimputables. El cual consideramos que tiene mayor claridad y está mejor organizado en cuanto al procedimiento que se le debe de dar a los inimputables. 


\section{http://revistainvestigacionacademicasinfrontera.com}

A diferencia, el sistema tradicional penal no respetaba el debido proceso que marca la ley y conforme al código penal utilizaba conceptos que ya no deben de ser utilizados ya que se escuchaban de una forma ciertamente ofensivas al momento de referirse a la persona inimputable. Este sistema tradicional no era lo suficientemente claro en cuanto al procedimiento ya que dejaba al juez juzgarlo de la manera que más le convenía así mismo consideramos que caía en violación al artículo 14 constitucional el cual nos garantiza tener un respectivo debido proceso.

Si la capacidad psíquica de una persona de comprender la antijuricidad de su conducta y de no adecuarse a la misma algunas veces el sujeto que es imputable conforme a las averiguaciones previas establecidas en código nacional de procedimientos penales se convierte en una persona inimputable. $Y$ como inimputabilidad comprendimos que son aquellas situaciones que si la conducta del sujeto es típica y antijurídica, hace que no se pueda atribuir el acto realizado al sujeto por acudir a la acción penal, por alguna enfermedad mental transitoria o permanente o por insuficiencia de la inteligencia.

\section{Bibliografía}

Medina Narváez, J. Á. (2016). Derecho Penal. apuntes de la parte general para el procedimiento acusatorio adversarial. México D.F.: Porrúa.

Estrada Álvarez . (2009). Los elementos del delito. México D.F: Angel editor.

Rodríguez Navarrete . (2016). Derecho penal. México D.F.: Porrúa. 